\section{Argumentação e livro didático: por uma parceria efetiva}

Argumentation and textbooks: for an effective partnership

Caroline Gomes MOTTA (UNISINOS) caroline.mottag@gmail.com Sabrina VIER (UNISINOS) sabrinavier@unisinos.br

Recebido em: 14 de set. de 2018. Aceito em: 15 de fev. de 2019.

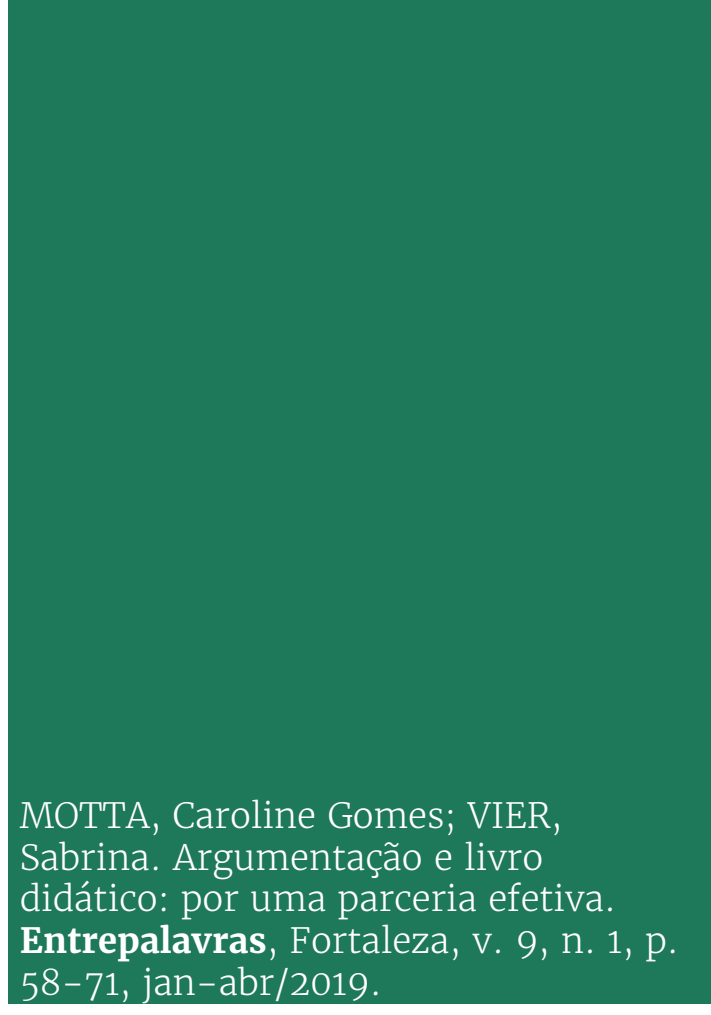

58-71, jan-abr/2019.

Resumo: Planejar uma aula sobre argumentação, principalmente para a Educação Básica, é um desafio que precisa ser encarado pelo professor de Língua de Portuguesa - ainda mais se pensarmos o papel dessa prática social proposto na Base Comum Curricular Nacional. Tendo por base a Teoria Semiolinguística, de Patrick Chauraudeau, objetivou-se verificar se as atividades propostas nos livros didáticos de $6^{\circ}$ a $9^{\circ}$ ano do Ensino Fundamental dão o suporte necessário para o desenvolvimento de senso crítico nos alunos. Para tal, serão apresentados os resultados obtidos a partir de análise da coleção "Português - Linguagens", de William Cereja e Thereza Cochar por meio de pesquisa quantitativa e qualitativa. Os resultados obtidos indicam que os professores precisam extrapolar o livro didático, pois as atividades ali presentes não dão conta de abordar a argumentação como prática social, tornando a tarefa de desenvolver o senso crítico nos alunos pouco efetiva.

Palavras-chave: Argumentação. Livro Didático. Prática Social. 
Abstract: Planning a class about argumentation, especially for Basic Education, is a challenge that must be faced by the Portuguese Language teacher - even more if we consider the role of this social practice proposed in the National Curricular Common Base. Based on Patrick Chauraudeau's Semiolinguistic Theory, our objective was to verify if the activities proposed in the textbooks of grades from 6 to 9 of Elementary School give the necessary support for the development of critical sense in the students. In order to do that, we will present the results obtained from the analysis of the collection "Português - Linguagens", by William Cereja and Thereza Cochar through quantitative and qualitative research. The results indicate that teachers need to extrapolate the textbook, because the activities included do not address argumentation as a social practice, making the task of developing critical sense in students little effective.

Keywords: Argumentation. Textbook. Social Practice.

\section{Introdução}

A Base Nacional Comum Curricular (BNCC) afirma que "[...] é importante fortalecer a autonomia [dos] adolescentes, oferecendolhes condições e ferramentas para acessar e interagir criticamente com diferentes conhecimentos e fontes de informação" (BRASIL, 2017, p. 58). Nesse sentido, estipula, para o ensino de Língua Portuguesa, competências gerais, específicas da área das linguagens e da área de Língua Portuguesa para o Ensino Fundamental. Dentre as competências gerais, destaca-se a necessidade de que o aluno aja

[...] com autonomia, responsabilidade, flexibilidade, resiliência e determinação, tomando decisões, com base nos conhecimentos construídos na escola, segundo princípios éticos democráticos, inclusivos, sustentáveis e solidários. (BRASIL, 2017, p. 18).

Logo, se "[...] ser competente significa ser capaz de, ao se defrontar com um problema, ativar e utilizar o conhecimento construído" (BRASIL, 2017, p. 16), torna-se imprescindível que o professor esteja preparado e qualificado para desenvolver a competência argumentativa em sala de aula, ensinando os estudantes a agirem no mundo com discernimento e a exercerem a cidadania de modo efetivo, responsável e ético.

Tratar de argumentação é certamente um desafio docente, mas um desafio necessário e de extrema importância se considerarmos que a escola deve almejar a formação de cidadãos críticos e com competência para se articularem nas mais diversas situações da vida cotidiana. Mas engana-se quem busca a maneira certa de ensinar argumentação, pois não há uma "[...] maneira ideal de argumentar" (CHARAUDEAU, 2004, p. 44). Assim, neste artigo, procuramos, além de ressaltar a importância 
v. 9 (1)

58-71

jan-abr

2019

do trabalho com argumentação na escola, pensar um caminho possível para o ensino dessa atividade linguageira por meio da Teoria Semiolinguística proposta pelo linguista francês Patrick Charaudeau. A escolha por essa teoria se deve porque entendemos que a argumentação é uma prática social e, como tal, precisa ser estudada tendo em vista a situação de comunicação e a relação intrínseca entre forma e sentido.

Para nosso estudo ${ }^{1}$, elegemos a mídia como foco pela necessidade de olharmos para essa prática que tanto circula entre nossos alunos e que a BNCC apresenta como uma questão importante de ser trabalhada e problematizada na escola, uma vez que esta tem o papel de contribuir "[...] para o desenvolvimento, no estudante, de uma atitude crítica em relação ao conteúdo e à multiplicidade de ofertas midiáticas e digitais" (BRASIL, 2017, p. 58).

Além disso, conforme Motta (2017, p. 18), a mídia tem sido "[...] alvo constante de críticas populares nos últimos anos, logo a problematização dos gêneros textuais que nela circulam torna-se cada vez mais relevante para a sala de aula". Dessa forma, há contradição e equívoco ao considerar a imparcialidade como um pressuposto da mídia, já que a argumentação é intrínseca à linguagem, então, por mais imparcial que um discurso possa parecer, "[...] a simples seleção das opiniões a serem reproduzidas já implica, por si mesma, uma opção." (KOCH, 2011, p. 18).

Por fim, buscamos na coleção Português - Linguagens, de William Cereja e Thereza Cochar, indicada pelo Programa Nacional do Livro Didático (PNLD), uma forma possível de pensar a argumentação como prática social por meio do trabalho com gêneros textuais presentes na mídia. A escolha dessa coleção leva em consideração as resenhas do material, que ressaltam a

[...] diversidade de gêneros, principalmente das esferas literária e jornalística, e de temas contemplados, além da adequação das abordagens ao público-alvo, os estudantes, em cada nível de ensino. (MOTTA, 2017, p. 50).

Além disso, o guia também acrescenta que "[...] a coleção explora elementos de textualidade, dentre eles a argumentatividade" (MOTTA, 2017, p. 50). Mediante tais informações, consideramos a coleção um bom material para ser utilizado como estudo e como possibilidade de pensar a argumentação na escola.

${ }^{1}$ Este artigo apresenta um recorte de estudo desenvolvido por Motta (2017) em seu trabalho de conclusão de curso. 
Assim, primeiramente, traremos a Teoria Semiolinguística como uma possibilidade de trabalhar a argumentação na escola. Com base nessa teoria e nas resenhas dos livros didáticos aprovados pelo PNLD para o triênio 2017-2019, serão realizados estudos quantitativos e qualitativos. A fim de ter clareza dos gêneros textuais que comparecem na coleção, serão elencadas as ocorrências de textos midiáticos na coleção Português - Linguagens. Em seguida, em pesquisa qualitativa, será problematizada uma atividade com texto de divulgação científica. Ambas as abordagens visam verificar se as atividades propostas dão suporte para o professor de Língua Portuguesa planejar aulas que pensem a argumentação como prática social. Por fim, traremos alguns pontos para pensarmos o uso do livro didático e o trabalho com a argumentação no Ensino Fundamental.

\section{Argumentação}

Trabalhar com argumentação nas aulas de Língua Portuguesa é um desafio, uma tarefa ardilosa para os professores, que precisa ser encarado e problematizado, mesmo que saibamos, em diálogo com Charaudeau (2004), que toda questão relativa à linguagem seja complexa. Essa constatação, então, muito antes de inviabilizar o trabalho com argumentação, solicita que tenhamos claro o desafio que essa prática linguageira nos coloca: transcender a forma para encontrar o sentido.

Giering (2003) indica-nos uma direção ao orientar a Teoria Semiolinguística como possibilidade para o ensino de argumentação nas escolas, uma vez que tal teoria permite "[...] a articulação da ação pedagógica de ensino da argumentação com o contexto de comunicação no qual a atividade argumentativa se insere" (GIERING, 2003, p. 215). Se a argumentação não é mera forma, nas escolas conhecida como introdução-desenvolvimento-conclusão, mas uma atividade linguageira, é imprescindível que trabalhemos por meio de competências discursivas. Isso porque a argumentação envolve condições de uma atividade linguageira e não um tipo de texto (CHARAUDEAU, 2004).

Nesse viés, Giering (2003) indica três níveis de ação para o trabalho: competência situacional, competência discursiva e competência semiolinguística. Tais níveis, diretamente relacionados e inseparáveis quando se trata do efeito argumentativo de um texto, são necessários para o ensino efetivo em sala de aula, a fim de tornar os estudantes cidadãos competentes para agirem no mundo e exercerem sua cidadania com aptidão e responsabilidade. 
v. 9 (1)

58-71

jan-abr

2019

A competência situacional consiste no contrato estabelecido em determinada situação de comunicação, também denominado como Contrato de Comunicação. Segundo Charaudeau (2004, p. 37):

[...] todo ato de linguagem só tem significado em função da situação de comunicação na qual ele é produzido, de identidade e da intencionalidade do sujeito que é o responsável por ele, do tema de que trata (a tematização) e de circunstâncias materiais em que ele se encontra.

Assim, o contrato de comunicação coloca em cena que há restrições da situação que dizem da argumentação e não da forma do texto, ou seja, é o contrato de comunicação que determina a qualidade da argumentação e não o tipo de texto. E, neste estudo, importa-nos o contrato estabelecido em textos midiáticos. Segundo Motta (2017, p.34):

[...] o contrato de informação midiática pressupõe um sujeito comunicante, que deve ser um profissional do jornalismo que atenda a certas exigências do suporte no qual veiculará seu texto e descrever/narrar e explicar um acontecimento do mundo a fim de despertar, no maior número de sujeitos interpretantes possíveis, que são os destinatários do seu texto, o interesse de ler sobre o assunto.

Nesse sentido, entendemos que as atividades propostas aos estudantes diante de textos dessa esfera devem considerar o contrato de informação midiática como um item a ser estudado com os alunos para posterior problematização, propiciando um processo evolutivo de aprendizagem, colocando o estudante como um leitor ativo, que não está alheio às condições de produção e recepção dos textos aos quais tem acesso pela mídia e que tem capacidade de avaliar se o conteúdo dessas informações pode ser considerado como verdadeiro de acordo com a credibilidade de quem comunica, onde e com que objetivo. A competência situacional, como o próprio nome infere, situa, então, o estudante diante da prática social.

A competência discursiva consiste, segundo Giering (2003), na tríplice problematizar-elucidar-provar, refutando a ideia de que os alunos devem produzir textos dissertativo-argumentativos com uma estrutura única e engessada. Para que um discurso seja compreendido como argumentativo, é necessário que o sujeito argumentador empreenda essa tripla atividade: fazer-saber (problematizar), fazercompreender (elucidar) e fazer-crer (provar) (CHARAUDEAU, 2004). Assim, o aluno deve ter desenvolvida a capacidade de "manipular e reconhecer as estratégias de encenação relacionadas às necessidades 
inerentes ao quadro situacional" (GIERING, 2003, p. 218). Ter clareza sobre esse processo é importante tanto para o reconhecimento dos argumentos, nas informações veiculadas pela e na mídia, quanto para o desenvolvimento da habilidade dos estudantes de argumentarem sobre determinado tema ou assunto.

Portanto, a tripla atividade, conforme Charaudeau (2004, 2009), corresponde a um modo de organização do discurso, que pode ser escrito ou oral, no qual se parte de uma problematização sobre algo do mundo, em um movimento que o autor denomina "fazer-saber". No contrato midiático, essa primeira atividade pode ocorrer sob três formas:

[...] uma pergunta [...]; várias asserções que se combinam, como um pré-título precedendo o título [...]; uma dupla asserção apresentada como uma alternativa" (CHARAUDEAU, 2009, p. 178).

É a partir dessa atividade que se inicia o processo de argumentação, seguindo-se a elucidação como intermediária para se chegar a uma conclusão. A elucidação também é denominada "fazercompreender", porque é o momento em que o autor de um texto argumentativo esclarece

[...] o que não se vê, o que está oculto, o que é latente, e que constitui as razões mais ou menos profundas do surgimento do fato. Esse oculto, esse latente, é o que as mídias se propõem fazer emergir, para fornecer ao consumidor de informação as circunstâncias e as implicações do fato. Isso pode ser obtido tanto desvendando as intenções, os motivos que animaram os protagonistas dos acontecimentos, quanto expondo suas causas externas. (CHARAUDEAU, 2009, p. 178).

Essa segunda atividade, portanto, tem o objetivo de ampliar os conhecimentos do leitor sobre o tema problematizado, logo é direcionada pelo autor, no caso, alguém da mídia, para que o leitor concorde com os argumentos da informação veiculada a partir de uma reconstituição de fatos ou de raciocínio por analogia (CHARAUDEAU, 2009). Destacamos a importância da tomada de consciência dos estudantes sobre essa segunda atividade, uma vez que as informações reproduzidas nessa etapa consistem em escolhas próprias de quem informa, com o objetivo específico, e podemos também dizer restrito, de provar a verdade de seu discurso, seu ponto de vista.

A terceira atividade é chamada por Charaudeau (2004; 2009) de avaliação, prova ou "fazer-crer". Essa atividade é a última etapa do processo, sendo então a conclusão do(s) argumento(s) defendido(s) porque 
v. 9 (1)

58-71

jan-abr

2019

informa e "[...] refere-se ao ponto de vista pessoal do sujeito comunicante" (MOTTA, 2017, p. 26), que necessariamente vai indicar uma ideologia, pois Charaudeau (2009, p. 180) ressalta que, referente ao autor ou ao suporte em que a informação foi veiculada, essa etapa pode estar "[...] expondo sua própria opinião [...], ou formulando uma apreciação subjetiva (projeção de sua subjetividade)" (CHARAUDEAU, 2009, p. 180). Fica claro, a partir deste estudo, que essa etapa não é um posicionamento imparcial da mídia. Sendo assim, mais uma vez, ressaltamos a importância da mediação do professor para o desenvolvimento da criticidade dos educandos frente a essa estratégia textual.

Por último, a competência semiolinguística, que justamente é extrapolar a forma pela forma, "[...] relaciona-se ao manipularreconhecer as formas dos signos, suas regras e seus sentidos conforme os elementos do quadro situacional e das exigências da organização do discurso" (GIERING, 2003, p. 218), para encontrar o sentido do texto, a argumentação como prática social.

Para trabalhar com argumentação, então, é preciso transcender a forma explícita que até então se aborda na escola, para encontrar as condições que a colocam como prática linguageira, como prática social que envolve uma situação de comunicação específica que visa um fazercrer singular.

\section{Livro didático e argumentação}

Tendo em vista a necessidade de um trabalho potente com o livro didático, material distribuído pelo Ministério da Educação por intermédio do Programa Nacional do Livro Didático (PNLD) e disponibilizado, em razoáveis quantidades, para cada nível escolar, torna-se relevante analisar como esses livros possibilitam o trabalho com argumentação nas coleções de Educação Básica.

Para pensar esse trabalho mediante a coleção Português Linguagens, primeiramente, realizamos um mapeamento dos gêneros discursivos midiáticos encontrados em toda a coleção, do $6^{\circ}$ ao $9^{\circ}$ ano do Ensino Fundamental, a fim de ter clareza sobre a diversidade desses gêneros, obtendo os resultados apresentados na Figura 1. 
Figura 1 - Ocorrências de gêneros do discurso da mídia²

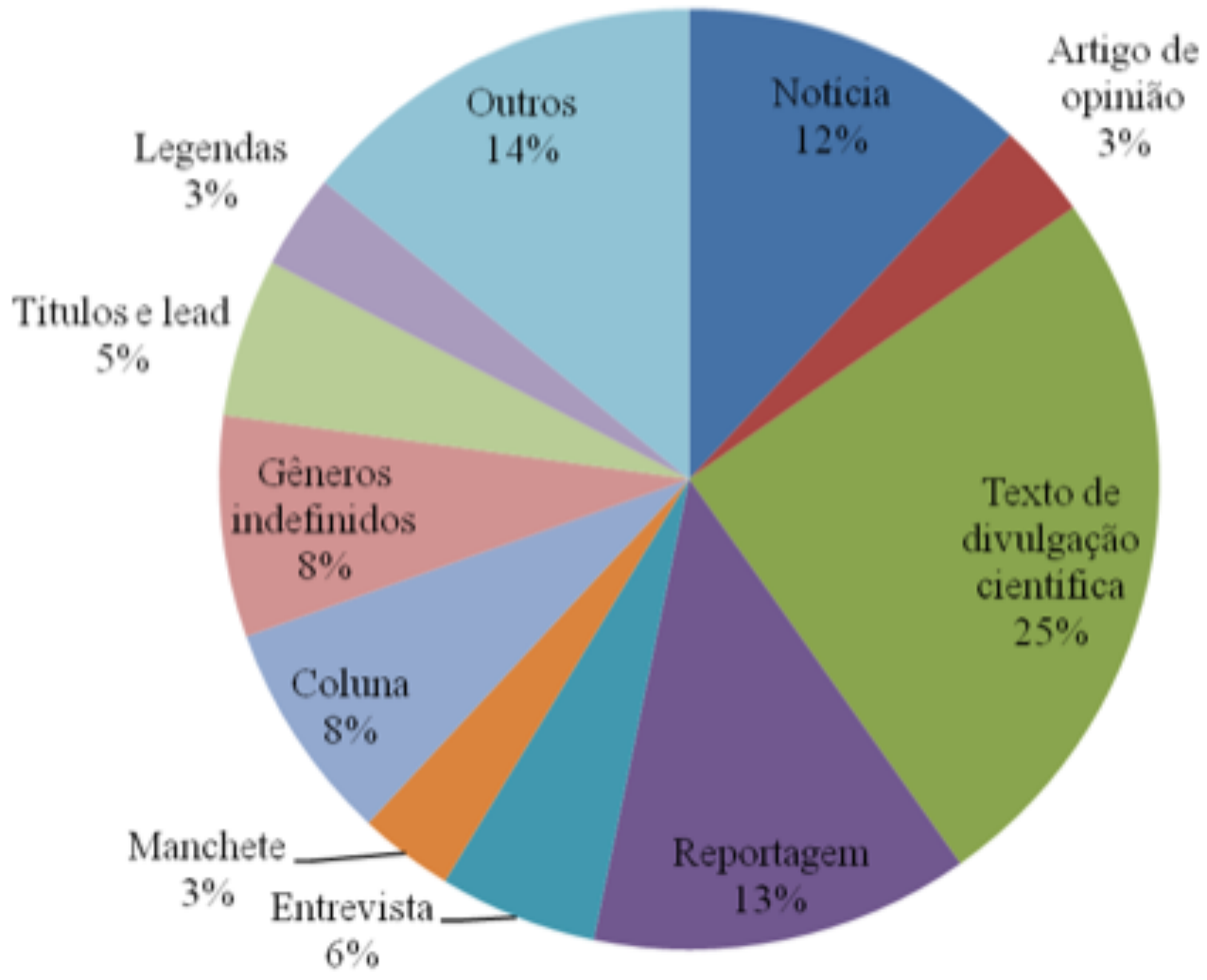

Fonte: Motta (2017, p. 66).

Foram identificados 83 textos da mídia na coleção, sendo mais evidenciados os textos de divulgação científica, com $25 \%$ das ocorrências, seguidos da reportagem, com 13\% de ocorrências, e a notícia com $12 \%$ das ocorrências.

A Figura 1 comprova, então, a informação do Guia PNLD de que o livro Português - Linguagens apresenta uma diversidade de gêneros, em especial das esferas literária e midiática. Entretanto, notase que, em diversas ocorrências, os textos encontram-se fragmentados, não podendo ser reconhecidos como gêneros textuais ( $8 \%$ de gêneros indefinidos). Essa característica, provavelmente devido a questões editoriais, prejudica a compreensão global do texto e de sua construção argumentativa - como reconhecer as competências propostas por Giering (2003)? Se um texto está fragmentado, o trabalho com as competências situacional, discursiva e semiolinguística está, pois, inviabilizado - e também o trabalho com a argumentação.

Para termos uma noção mais concreta acerca dos textos fragmentados, realizamos um levantamento que resultou na Figura 2.

\footnotetext{
${ }^{2}$ Na categoria "Outros" se enquadram os textos com apenas uma ocorrência e as atividades acerca de discurso das mídias que não apresentavam textos midiáticos e a seção "Manual do professor".
} 
V. 9 (1)

58-71 jan-abr 2019

Figura 2 - Ocorrências de textos na íntegra e de textos fragmentados

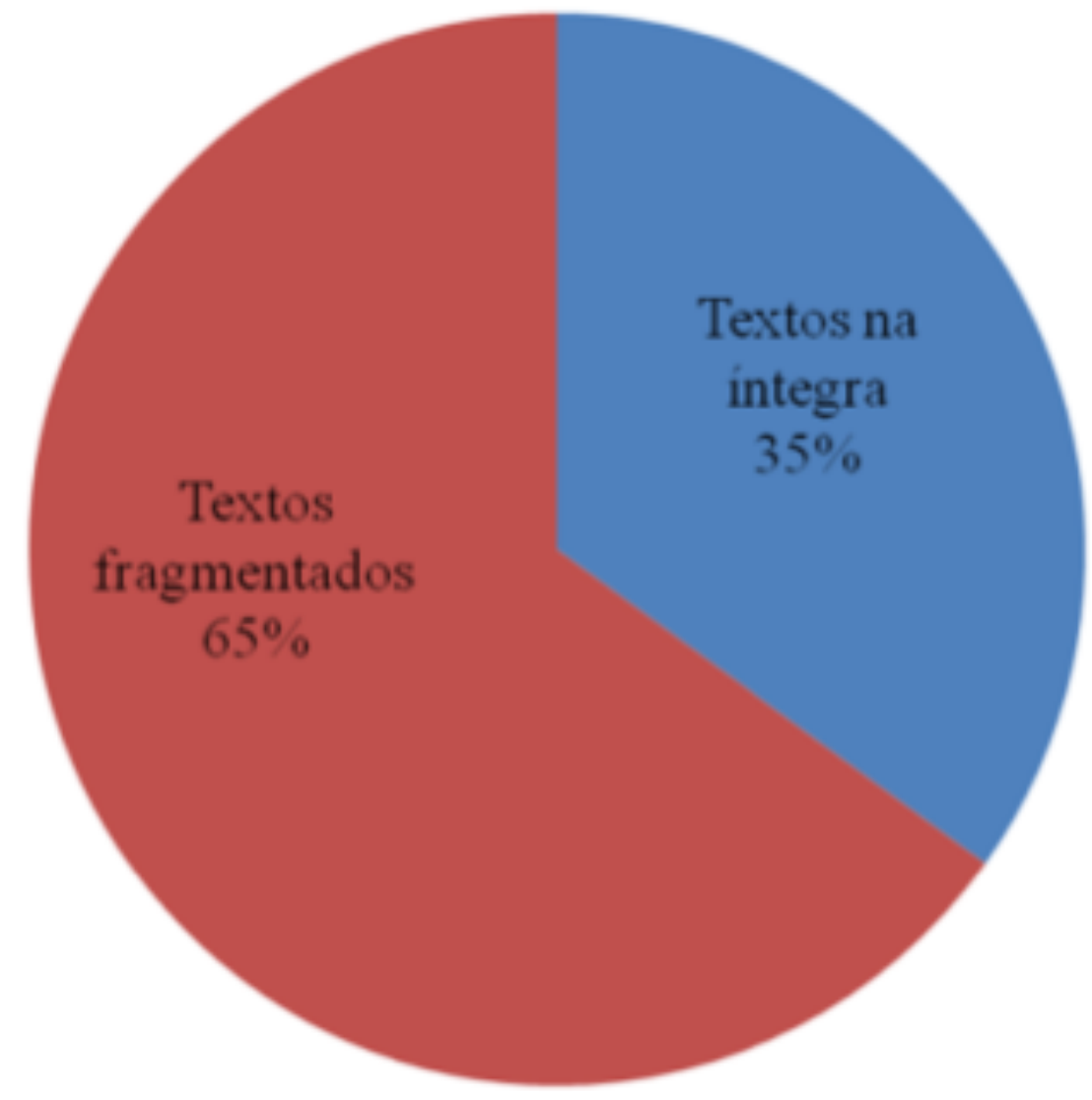

66

Fonte: Motta (2017, p. 65).

Evidencia-se o excesso de textos fragmentados, 65\%, que corresponde a um total de 54 textos fragmentados de um total de 83. Especificamente, por nível de ensino, podemos observar o que consta no Quadro 1.

Quadro 1: Textos fragmentados por nível de ensino

\begin{tabular}{ccc}
\hline Nível de ensino & Total de ocorrências & $\begin{array}{c}\text { Quantidade de textos } \\
\text { fragmentados }\end{array}$ \\
\hline $6^{0}$ ano & 16 & 9 \\
$7^{0}$ ano & 23 & 17 \\
$8^{0}$ ano & 23 & 11 \\
$9^{\circ}$ ano & 21 & 17 \\
\hline
\end{tabular}

Fonte: Motta (2017).

Podemos observar, a partir do Quadro 1, que há um número excessivo de textos fragmentados em todos os níveis de ensino da coleção. E o que isso nos diz do trabalho em sala de aula? 
Ora, se a informação midiática, conforme Charaudeau (2009), já é um fragmento da realidade, então apresentar trechos de textos aos estudantes é apresentá-los a fragmentos de um fragmento de determinada realidade e, assim, talvez utilizar o texto apenas como pretexto para propostas de atividades, muitas vezes, de tópicos gramaticais descontextualizados ou de temáticas manipuladas. (MOTTA, 2017, p. 66).

Nesse sentido, constatamos que a fragmentação dos textos midiáticos prejudica - ou até mesmo inviabiliza - o ensino de argumentação em sala de aula. Se o livro didático indica a fonte original do texto, o ideal seria que, ao planejar suas atividades, o professor buscasse pelo texto na íntegra e desenvolvesse um trabalho mais eficaz acerca das competências situacional, discursiva e semiolinguística. Mas será que essa é uma realidade possível nas escolas brasileiras? Ou, ainda, não seria papel do livro didático justamente dar suporte ao trabalho docente?

Com a intenção de problematizar o trabalho com argumentação a partir de um gênero textual midiático, selecionamos atividades propostas para um texto na íntegra. Além disso, após estudo minucioso da coleção, julgamos esta proposta, comparada a todas as demais ocorrências de textos de divulgação científica, a mais completa em relação as três competências propostas por Giering (2003). Para chegarmos à conclusão de que a atividade selecionada, a ser apresentada a seguir, é a mais completa, na análise das ocorrências de textos de divulgação científica, utilizamos três perguntas norteadoras:

a) as atividades convidam o aluno a pensar o contrato de comunicação?

b) as propostas abordam o fazer-saber, o fazer-compreender e o fazer-crer?

c) as atividades propõem a análise linguística tendo em vista o quadro situacional?

Essas perguntas foram o ponto de partida para estudo de todos os textos de divulgação científica na íntegra presentes na coleção. Assim, escolhemos apresentar neste estudo a proposta de trabalho que identificamos que atendeu ao maior número de critérios das questões acima. Trata-se de um texto e de atividades de uma das seções de produção de texto do livro de $8^{\circ}$ ano da coleção, que serviu de parâmetro para pensarmos o trabalho com a argumentação como prática social. 
V. 9 (1)

58-71

jan-abr

2019

A atividade inicia com o texto intitulado "O vício de comer", do doutor Drauzio Varella, que ocupa duas páginas do livro com o texto, além de fotos ilustrativas relacionadas ao tema: uma jovem mordendo uma pizza, na primeira página, e outra com excesso de peso, na segunda página. No final do texto, há o link como referência do texto, link este que trata da página do próprio médico, e um pequeno glossário com vocábulos do texto que foram considerados, pelos organizadores da obra, como importantes de serem definidos aos alunos por talvez não fazer parte do vocabulário com o qual eles estariam acostumados. Após apresentação do texto, o livro propõe 11 exercícios dissertativos. Constatamos que as atividades propostas atendem, em parte, a alguns requisitos para trabalhar com argumentação na escola.

Primeiramente, o texto que dá origem à atividade é apresentado na íntegra, trazendo o nome do autor e o local em que o texto foi originalmente publicado, facilitando a compreensão da competência situacional. No entanto, não são solicitadas essas informações nas questões propostas pelo livro, ou seja, o aluno não é convidado a pensar sobre o contrato de comunicação.

As três questões subsequentes ao texto convidam o estudante para identificação da temática e da motivação do autor para a produção de seu texto: o atraso da medicina no tratamento da obesidade e as consequências sociais que isso gera - como o preconceito. Além disso, são apresentadas questões sobre a compreensão do conteúdo explícito no próprio texto. Todas as questões dessa parte iniciam com uma afirmativa e seguem com duas perguntas referentes a essa informação relacionada ao texto.

Em seguida, há oito perguntas de conhecimentos específicos sobre o gênero textual, que contemplam a finalidade do texto, sua estrutura, adequação linguística e ao público-alvo, adequação da variedade linguística ao assunto e suporte do texto. Por fim, uma pergunta que sugere que os alunos se reúnam em grupos para sistematização dos conhecimentos sobre o gênero textual. Essas 8 questões remetem brevemente às competências situacional e discursiva, mas não acionam a competência semiolinguística.

É importante destacar que a atividade, tal qual está proposta, faz com que os estudantes, por meio das perguntas, reflitam sobre a constituição do gênero textual a partir de questões específicas e sistematizem os conhecimentos de maneira colaborativa, o que rompe com uma estrutura tradicional do ensino, que se dá de maneira vertical, 
com o professor como o dono da informação, que a impõe aos alunos para que aprendam o que ele acha importante ensinar. Da forma como a atividade é proposta, há possibilidade de o conhecimento ser construído horizontal e colaborativamente, entre o professor e os alunos e entre os próprios alunos, sendo uma metodologia que consideramos mais eficiente e que está mais adequada ao perfil dos alunos de hoje.

Por fim, há dois exercícios sobre conhecimentos gramaticais que pedem apenas classificação de tempo e modo verbal, sem ativar a competência semiolinguística, relacionando o uso de verbos da $3^{\text {a }}$ pessoa à (im)parcialidade do autor frente ao que explicitou em seu texto. Aqui constatamos que a escolha do estudo dos verbos está muito mais para cumprir com o tópico do que com a análise do sentido do texto, ou seja, não se estuda a classe gramatical verbo porque ele participa da construção discursiva, mas porque é um conteúdo a ser abordado na escola. Além disso, é possível, ainda, se falar em texto imparcial? Se queremos formar cidadãos críticos não deveríamos trabalhar com nossos alunos que todo dizer implica um posicionamento?

Gostaríamos de marcar aqui que a questão da suposta imparcialidade do autor abordada pelo livro didático mostra o quanto o estudo da argumentação como prática social está distante das escolas - se tomarmos o livro didático como exemplar do que é trabalhado nas aulas de Língua Portuguesa. O que vemos nesse estudo é que as atividades propostas para o texto expõem a fragilidade do trabalho com atividades linguageiras, e, por isso, com a argumentação como prática social.

De modo geral, as competências situacional e discursiva são evidenciadas nas questões que trabalham os conhecimentos sobre o gênero textual, como na questão de número 3:

3) A estrutura de um texto de divulgação científica não é rígida, pois depende do assunto e de outros fatores da situação, como: quem produz o texto, para quem, em que veículo, com que finalidade. Apesar disso, normalmente o autor apresenta uma ideia principal - geralmente um conceito ou um ponto de vista sobre um conceito - e procura fundamentá-la com "provas" ou evidências, isto é, exemplos, comparações, resultados objetivos de experiências, dados estatísticos, relações de causa e efeito, etc. No texto "O vício de comer":

a) Qual é a ideia principal que o autor desenvolve?

b) Por que, segundo o autor, tratamentos médicos têm dado pouco resultado? (CEREJA; MAGALHÃES, 2015, p. 211). 
V. $9(1)$

58-71

jan-abr 2019

No entanto, o professor precisa ampliar e aperfeiçoar seu planejamento ao apresentar para os alunos novas perguntas sobre credibilidade do autor (Quem é Drauzio Varella? Por que os estudantes devem confiar no texto escrito por ele?) e do suporte do texto (A fonte do texto é confiável? Por que e como sei se essa fonte é confiável?), explorando, assim, a tríplice problematizar-elucidar-provar para mostrar aos alunos como esse movimento funciona no texto. Afinal, a argumentação é uma prática social.

Se a atividade analisada é, no nosso entendimento a mais completa, de modo geral, essa coleção não explora a argumentação como prática linguageira. Isso demonstra que os professores precisam utilizar o livro didático como suporte para o planejamento de suas aulas, mas não devem se limitar apenas às propostas didáticas do livro: é preciso extrapolar o material, trazendo questões adicionais que convidem o aluno a pensar sobre a argumentação como atividade humana.

\section{Considerações finais}

O ensino de argumentação não deve focar textos dissertativoargumentativos que exigem uma estrutura engessada na sequência introdução-desenvolvimento-conclusão. Se a argumentação é uma prática linguageira, então o trabalho com argumentação está muito mais para experiência humana do que para marcas linguísticas - a argumentação é um modo de organização do discurso.

Nesse sentido, sugerimos que o livro didático seja visto pelo professor como um material de apoio, não um manual de ensino. Isso porque as atividades propostas precisam ser extrapoladas para que os estudantes tenham acesso a um ensino de qualidade sobre argumentação, tendo, assim, discernimento para lidar com as informações da mídia, por exemplo.

Concluímos que há muito trabalho a ser feito para que as propostas didáticas presentes no livro didático contemplem um trabalho efetivo de argumentação, a fim de fortalecer a autonomia e o senso crítico dos adolescentes, previstos pela BNCC, frente às informações e ao conhecimento que circulam nos textos. 


\section{Referências}

BRASIL. Ministério da Educação. Base Nacional Comum Curricular. Proposta preliminar. Terceira versão revista. Brasília: MEC, 2017, p. 59149. Disponível em: <http://basenacionalcomum.mec.gov.br/a-base>. Acesso em: 27 abr. 2017.

CEREJA, W. R.; MAGALHÃES, T. C. Português - Linguagens: $8^{\circ}$ ano. 9. ed. São Paulo: Saraiva Educação, 2015.

CHARAUDEAU, P. A argumentação talvez não seja o que parece ser. In: GIERING, M. E.; TEIXEIRA, M. Investigando a linguagem em uso. São Leopoldo, Unisinos, 2004, p. 33-44.

Discurso das mídias. Tradução de Angela S. M. Corrêa. 1. ed. $2^{\text {a }}$ reimpressão. São Paulo: Contexto, 2009.

GIERING, M. E. Orientações para o trabalho com argumentação escrita na escola numa perspectiva semiolinguística. Letras de Hoje, Porto Alegre, v. 39, n. 3, p. 215-225, 2003.

KOCH, I. G. V. Argumentação e linguagem. 13. ed. São Paulo: Cortez, 2011.

MOTTA, C. G. Discurso das mídias e livro didático: a formação de leitores críticos na escola. 2017. 127 f. Trabalho de Conclusão de Curso (Licenciatura em Letras - Português) - Curso de Letras, Universidade do Vale do Rio dos Sinos (UNISINOS), São Leopoldo, 2017. 